\title{
Evaluating Students Attitude and their Academic Performance on Social Media: A Cross-Sectional Study
}

\author{
R. Jayaseelan ${ }^{1}$, C. Pichandy ${ }^{2}$, \& N. Boobalakrishnan ${ }^{3}$ \\ ${ }^{1}$ Assistant Professor, Department of Visual Communication and Electronic Media, \\ PSG College of Arts \& Science, India. Email: jayaseelan.sr@gmail.com \\ ${ }^{2}$ Former Professor and Head, Department of Journalism and Mass Communication, \\ PSG College of Arts \& Science, India. Email: pichaandy@yahoo.co.in \\ ${ }^{3}$ Assistant Professor, Department of Media and Communication, \\ Central University of Tamil Nadu, India. Email: boobalakrishnan@cutn.ac.in
}

Area/Section: Communication Management.

Type of the Paper: Research Paper.

Type of Review: Peer Reviewed as per $|\mathrm{C}| \mathrm{O}|\mathrm{P}| \mathrm{E} \mid$ guidance.

Indexed in: OpenAIRE.

DOI: http://doi.org/10.5281/zenodo.3762942.

Google Scholar Citation: IJMTS.

How to Cite this Paper:

Jayaseelan, R., Pichandy, P., \&Boobalakrishnan, N. (2020). Evaluating Students Attitude and their Academic Performance on Social Media: A Cross-Sectional Study. International Journal of Management, Technology, and Social Sciences (IJMTS), 5(1), 101-109.

DOI: http://doi.org/10.5281/zenodo.3762942.

International Journal of Management, Technology, and Social Sciences (IJMTS)

A Refereed International Journal of Srinivas University, India.

(C) With Authors.

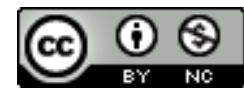

This work is licensed under a Creative Commons Attribution-Non-Commercial 4.0 International License subject to proper citation to the publication source of the work.

Disclaimer: The scholarly papers as reviewed and published by the Srinivas Publications (S.P.), India are the views and opinions of their respective authors and are not the views or opinions of the SP. The SP disclaims of any harm or loss caused due to the published content to any party. 


\title{
Evaluating Students Attitude and their Academic Performance on Social Media: A Cross-Sectional Study
}

\author{
R. Jayaseelan ${ }^{1}$, C. Pichandy ${ }^{2}$, \& N. Boobalakrishnan ${ }^{3}$ \\ ${ }^{1}$ Assistant Professor, Department of Visual Communication and Electronic Media, \\ PSG College of Arts \& Science, India. Email: jayaseelan.sr@gmail.com \\ ${ }^{2}$ Former Professor and Head, Department of Journalism and Mass Communication, \\ PSG College of Arts \& Science, India. Email: pichaandy@yahoo.co.in \\ ${ }^{3}$ Assistant Professor, Department of Media and Communication, \\ Central University of Tamil Nadu, India. Email: boobalakrishnan@cutn.ac.in
}

\begin{abstract}
Information and Communication technology has played a vital role in various aspects of our life. In our present study, we focus on the impact of ICT in communication, education and learning. ICT ushers with both negative and positive impacts on the life of humans. It influences students' knowledge, attitude and skill. ICT promotes a learning environment, among teachers and students, by providing virtual space and experience, mediated through technology. Smart classroom induces interest, elicits students' attention, elevates their understanding capacity, grasping skills and memory, with the help of multimedia teaching aids. It brings focus to the topic. In this fast-moving technology mediated world, usage of mobile phones and social media has become inexorable. The global phenomenon-anytime, anywhere learning —is made possible because of the ubiquity of smartphones. With traditional classroom learning on one side, social media platforms, on the other side, are providing virtual spaces for unconventional and collaborative learning. Students choose such technologies as supportive alternatives for their academic-intended communication with teachers and peers. Through this study, the researchers aim to measure the attitude of college students towards social media and the related influence on their academic performance, with reference to Coimbatore region. A survey was conducted among 507 college students from Coimbatore, chosen through a multistage stratified random sampling technique. The demographic variables-including age, gender and educational qualification and the dependent variables-included Academic performance, Time spent on social media per day, Time spent on social media during weekdays, Time spent on social media during weekends. Further result states that there is sizeable relationship between the employed social media attitude variables and the academic performance of the students, and no relationship with the time spent on social media. However, it was found that among social media attitudes, addictiveness and communication are the best predictors of academic performance.
\end{abstract}

Keywords: Social media, Students’ attitude, Academic performance, Social media exposure.

1. INTRODUCTION AND REVIEW OF LITERATURE :

Based on the internet and mobile association of India (IAMAI) report, 119 million urban internet users in India regularly use social media platforms i.e. approximately $66 \%$ of 180 million users. Primarily they access online media to maintain their - Facebook profile, twitter posts, Instagram post, etc., - stable virtual presence. Out of all social media users, largest demographic of active social media users are college students, whereas non-working and working women constitute of $11 \%$ and $7 \%$ of social media users. Describes ICT has developed 
the learning process as it has made it cheaper, faster, accessibility which was not possible before. The collaborative learning atmosphere provided by ICT produces better results. The advancement and omnipresence of technology support and assists to make universal pedagogy[1].

Findings provide insight about the academics who use social media in the sophisticated and proposed action through which they have gained experience and benefits[2]. The benefits not only denote the establishment of connective and sharing of experience within the university but also with other universities, and other educational institutions through which we can develop and enhance research works.

States that the onslaught of new media technology, the rapid growth ofthe Internet and the emergence of the World Wide Web (WWW) have remarkable changes in the field of education[3]. Apart from formal learning, students have ample opportunities to acquire knowledge and to learn from social media. States the merits of the e-learning process- it enhances the quality of education, improves the interactive teaching and knowledge acquisition process[4].

This study mentioned that the emergence of computershas paved the way for instant scoring and instant feedback which helps students to score well[5].Illustrated that the subtitles used in the virtual learning videos are distracting the learners and it also reduces or hinders the learners listening ability[6]. On the contrary, subtitle helps the listeners to improve their language proficiency and it also increases their vocabulary. States that evaluation of the academic performance of students in higher education primarily involves a complex interrelationship between the students' accreditation and the educational environment[7].

The result suggested that motivation and study time are the non-ability variable that significantly affects the academic performance of college students[8]. Contradicting the popular credence, academic performance of students is not directly influenced by the amount of time they spend on studying. States that have implementation intention of students has a positive effect on their goal attainment[9]. Study states that the achievement relates context has three common properties like- locus, stability and controllability[10]. Researchers mentioned that inadequate study skills, poor management of time, their internal and external motivation are some of the aspects of students' underachievement in studies[11].

Findings provide evidence that cognitive, volitional and motivational strategies are used by the students to regulate their effort and hard work to improve their academic performance[11]. Students' motivational regulations were positively related to their use of some cognitive strategies, goal orientation and academic performance. It is disclosed that the time management skills of students and the amount of their study time are constructively associated with their GPA[12]. The results suggest that the academic performance of college students increases substantially with increased study time.

Researchers mentioned that perceptions of the students about the classroom structures are much more important for their motivation and confidence[13]. It was also supported by the students' perception of current classwork as an instrument for their success in the future. The study states that students' academic performance was measured through students' self-efficacy, test anxiety, intrinsic value, self-regulation and the variety of learning strategies they use[14]. Self-efficacy and intrinsic value were positively related to cognitive engagement and performance. Out of all the factors, the performance was analysed better based on the outcome measure, self-efficacy, self-regulation and test anxiety.

Study mentioned that students prefer social media as a vital key for three purposes mainly[15]. They are named for sharing and retrieval of information (educational purpose), coordinating the group work (management skills), and to clarify the doubts. They also use social media to maintain their Facebook, Twitter, YouTube account and to constantly update their status. Findings state that student's development of social media websites, for the 
freshers who were about the join the college, would give them a virtual experience of the college atmosphere, and it gives them the confidence to cope with the college environment[16]. It helps in increasing the students' perception about the social support that extension the college campus.

It illustrates that students who are pursuing higher education perceive email as an important tool through which they can clarify doubts, share and exchange information and updates about their studies[17], [20]. The long-distance communication aspect of social media breaks the geographical barrier and helps students to get feedback and negotiation through which they can improve their studies or dissertation.

Findings indicate that when social media were used as an additional teaching aid, the majority of the students showed strong feelings towards social connectedness and also expressed favourable and positive when concerned with their learning experiences in the classroom environment[18], [19-21]. The study states that faculty members recognise that informal learning inhibited through social media could be assisted by faculty members[16]. Integrating social media into formal learning could, inturn, enrich discussion among students and also gives broad connections.

\section{OBJECTIVES OF THE STUDY :}

This study aims to identify and analyse the social media usage level, the attitude of college students towards social media and the academic performance of students among a cross-section of the college students in Coimbatore, Tamil
Nadu, India.

\section{RESEARCH QUESTIONS :}

Through a multistage stratified random sampling method, 507 college students were chosen for this study. Keeping the objective in mind the following research questions were raised:

RQ1: Is there any relationship between Accessibility, Addictiveness, Exposure, Communication, Academic Performance and Time spent on Social Media usage per day, on weekdays and on weekends?

$\mathrm{H}_{\mathrm{A}}$ : There is a relationship between Accessibility, Addictiveness, Exposure, Communication, Academic Performance, Time spent on Social Media usage per day, on weekdays and on weekends.

$\mathrm{H}_{0}$ : There is no relationship between Accessibility, Addictiveness, Exposure, Communication, Academic Performance, Time spent on Social Media usage per day, on weekdays and on weekends.

RQ2: How do college students social media attitudes(addictiveness, accessibility, exposure, communication) compare to their social media usage as a predictor of academic performance?

To answer the research question 1 and test the relationship among the students' attitude towards social media-accessibility, addictiveness, exposure, communicationacademic performance, Time spent on Social Media usage per day, Time spent on social media on weekdays and Time spent on social media on weekends, a correlation test was done and results are presented in the table 1 .

Table 1: Correlations between Accessibility, Addictiveness, Exposure, Communication,

Academic Performance, and Time spent on Social Media usage per day, Time spent on social media during weekdays and Time spent on social media during weekends

\begin{tabular}{|l|c|c|c|c|c|c|c|c|}
\hline & Accessibility & Addictiveness & Exposure & Communication & $\begin{array}{c}\text { Academic } \\
\text { Performance }\end{array}$ & $\begin{array}{c}\text { SM usage } \\
\text { per day }\end{array}$ & $\begin{array}{c}\text { SM during } \\
\text { weekdays }\end{array}$ & $\begin{array}{c}\text { SM during } \\
\text { weekends }\end{array}$ \\
\hline Accessibility & 1 & $.249^{* *}$ & $.270^{* *}$ & .011 & .073 & $-.171^{* *}$ & -.079 & $-.106^{*}$ \\
\hline Addictiveness & & 1 & $.135^{* *}$ & -.080 & $.169^{* *}$ & -.057 & -.059 & -.043 \\
\hline Exposure & & & 1 & $.273^{* *}$ & $.118^{* *}$ & -.012 & -.018 & -.030 \\
\hline
\end{tabular}




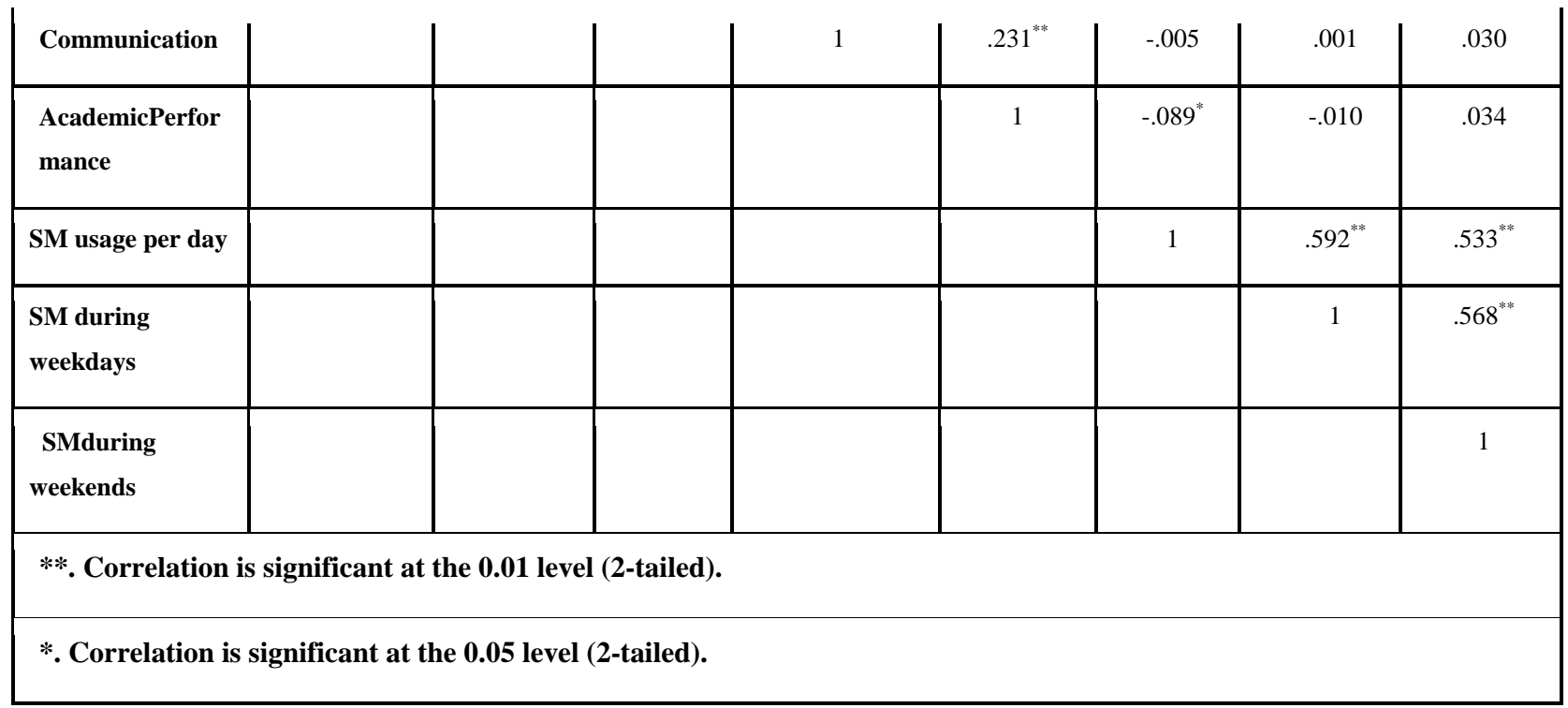

A bivariate correlation test was run to determine the relationship between the factors influencing Students' Attitude towards Social MediaAccessibility, Addictiveness, Exposure, Communication-Academic Performance and Time spent on social media per day, Time spent on social media during weekdays and Time spent on social media during weekends. There is a strong positive correlation between them, which was statistically significant $(\mathrm{N}=507$, $\mathrm{p}<0.05$ ).

Results revealed a strong, positive and statistically-significant correlation between accessibility and addictiveness $(\mathrm{r}=0.249, \mathrm{n}=$ 247, $\mathrm{p}<0.05$ ), accessibility and exposure ( $\mathrm{r}=$ $0.270, \mathrm{n}=247, \mathrm{p}<0.05$ ), accessibility and time spent on social media per day $(\mathrm{r}=-0.171, \mathrm{n}=$ 247, $\mathrm{p}<0.05$ ), accessibility and time spent on social media during weekends $(\mathrm{r}=-0.106, \mathrm{n}=$ 247, p <0.05). But there was no statistically positive, significant correlation between accessibility and communication $(\mathrm{r}=0.011, \mathrm{n}=$ 247, p <0.05), accessibility and academic performance $(r=0.073, n=247, p<0.05)$, accessibility and time spent on social media during weekdays ( $\mathrm{r}=-0.079, \mathrm{n}=247, \mathrm{p}<0.05$ ). It can be inferred that persons who have accessibility towards social media also have addictiveness and exposure towards social media, and accessibility also has effects in the amount of spent on social media per day and the amount of time spent during weekends.
However, there is no statistically significant correlation between accessibility, communication, academic performance and the amount of time spent on social media during weekdays.

Results revealed that there was a strong, positive and significant statistical correlation between addictiveness and exposure $(\mathrm{r}=0.135, \mathrm{n}=247$, $\mathrm{p} \quad$ 0.05), addictiveness and academic performance $(r=0.169, n=247, p<0.05)$. But there was no positive, statistically significant correlation between addictiveness and communication ( $\mathrm{r}=-0.080, \mathrm{n}=247, \mathrm{p}<0.05$ ), addictiveness and time spent on social media per day ( $\mathrm{r}=-0.057, \mathrm{n}=247, \mathrm{p}<0.05$ ), addictiveness towards time spent on social media during weekdays $(\mathrm{r}=-0.059, \mathrm{n}=247, \mathrm{p}<0.05)$, addictiveness and time spent on social media during weekends ( $\mathrm{r}=-0.043, \mathrm{n}=247, \mathrm{p}<0.05$ ). It can be inferred that persons who have addictiveness towards social media also have exposure towards social media and effects in academic performance. However, there is no statistically significant correlation between addictiveness towards social media, communication process, the amount of time spent on social media per day, the amount of time spent on social media during weekdays and weekends.

Results revealed that there was a strong, positive and significant statistical correlation between exposure and communication $(\mathrm{r}=0.273, \mathrm{n}=$ 
247, $\mathrm{p}<0.05)$, exposure towards social media and academic performance $(r=0.118, n=247$, $p$ $<0.05$ ). But there was no positive, statistically significant correlation between exposure and the time spent on social media per day $(\mathrm{r}=-0.012$, $\mathrm{n}$ $=247, \mathrm{p}<0.05$ ), exposure and the time spent on social media during weekdays $(\mathrm{r}=-0.018, \mathrm{n}=$ 247, $\mathrm{p}<0.05$ ), exposure and the time spent on social media during weekends $(\mathrm{r}=-0.030, \mathrm{n}=$ 247, p <0.05). It can be inferred that persons who have exposure to social media also have effects on the communication process and academic performance. However, there is no statistically significant correlation between exposure and the amount of time spent on social media per day, weekdays and weekends.

Results revealed that there was a strong, positive and significant statistical correlation between communication through social media and academic performance $(\mathrm{r}=0.231, \mathrm{n}=247, \mathrm{p}$ $<0.05$ ). But there was no positive, significant statistical correlation between communication and the time spent on social media per day ( $\mathrm{r}=$ $0.001, \mathrm{n}=247, \mathrm{p}<0.05$ ), communication and the time spent on social media during weekdays $(\mathrm{r}=$ $0.030, \mathrm{n}=247, \mathrm{p}<0.05$ ), communication and the time spent on social media during weekends ( $\mathrm{r}$ $=-0.005, \mathrm{n}=247, \mathrm{p}<0.05$ ). It can be inferred that persons who communicate through social media have effects on their academic performance. However, there is no statistically significant correlation between communication and the amount of time spent on social media per day, on weekdays and weekends.

Results revealed that there was a strong, positive and significant statistical correlation between academic performance though time spent on social media per day $(\mathrm{r}=-0.089, \mathrm{n}=247, \mathrm{p}$ $<0.05$ ). But there was no positive, statistically significant correlation between academic performance and the time spent on social media during weekdays $(\mathrm{r}=-0.010, \mathrm{n}=247, \mathrm{p}<0.05$ ), academic performance and the time spent on social media during weekends $(\mathrm{r}=0.034, \mathrm{n}=$ 247, p <0.05). It can be inferred that person's academic performance has effects due to the amount on time spent of social media per day. However, there is no statistically significant correlation between academic performance and the amount of time spent in social media during weekdays and weekends.

Results revealed that there was a strong, positive and significant statistical correlation between time spent on social media per day and during weekdays $(r=0.592, n=247, p<0.05)$, time spent on social media per day and during weekends ( $r=0.533, n=247, p<0.05)$. It can be inferred that persons who spent more time on social media per day also tend to spend more time in using social media during weekdays and weekends.

Results revealed that there was a strong, positive and significant statistical correlation between time spent on social media during weekdays and weekends ( $r=0.568, n=247, p<0.05)$. It can be inferred that persons who spent more time on social media during weekdays also spend more time on social media during weekends.

\section{REGRESSION ANALYSIS :}

Academic performance of the college students is based on the attitude towards social media and the time spent on it. Students' academic performances were recorded with the statement and options: "to a great extent", "somewhat", "very little", "not at all". These ordered responses were the categories of the dependent variable, academic performance. The students were asked to respond to a number of questions to measure their attitude towards social media (Addictiveness, Accessibility, Exposure, Communication) and time spent on social media. These variables were taken as the mediating variable. To answer research question 2, the present study performed the techniques reported by Baron and Kenny (1986) to identify the mediating variables. Social media attitude and usage mediate the relationship between demographic variables and academic performance. To test this kind of relationship, Baron and Kenny recommended three disparate regression equations to be estimated. Firstly, it must be made sure that demographic variables (gender, age, education) have an effect on social media attitude. Secondly, the demographics must be exposed to influence academic performance. Thirdly, social media attitude has to be shown to concern on academic 
performance. Further, by adding social media usage in the final equation, the prior significant relationship will weaken or disappear between demographic and academic performance.

The first regression equation evaluated the impact of demographic variables on social media attitude(accessibility, addictiveness, exposure, communication) presented in the below table. The result indicates that demographic variables (gender, age, education) account for $8 \%$ of the variance towards accessibility $(\mathrm{F}(3,503)=0.971, \mathrm{p}=0.406), 8 \%$ of variance in addictiveness $(\mathrm{F}(3,503)=1.096, \mathrm{p}$ $=0.350), 6 \%$ of variance in exposure $(\mathrm{F}(3,503)$ $=0.504, \mathrm{p}=0.679), 6 \%$ of variance towards communication $(\mathrm{F}(3,503)=0.615, \mathrm{p}=0.606)$. From the above results it is inferred that there is no significant effect on the social media attitude by the demographic variables.

The second regression equation involved the same demographic variables to evaluate their effect on academic performance. The results revealed that the demographics accounted for $17 \%$ of the variance in academic performance ( $\mathrm{F}$ $(3,503)=4.679, \mathrm{p}<0.01)$. Beta weights show there is a remarkable relationship between age, gender and academic performance and not with their education level (UG, PG).

Table 2: Standardized Beta Weights for Variables Predicting academic performance

\begin{tabular}{|c|c|}
\hline $\begin{array}{c}\text { Demographic } \\
\text { variables }\end{array}$ & $\begin{array}{c}\text { Academic } \\
\text { performance }\end{array}$ \\
\hline Age & $0.115^{*}$ \\
\hline Gender & $0.124^{* *}$ \\
\hline Education & 0.047 \\
\hline$* \mathrm{p}<0.05 * * \mathrm{p}<0.01$ & \\
\hline
\end{tabular}

Third, social media attitude evaluated with demographic variables must be shown to have an effect on academic performance. Third regression equation is performed with the demographic and social media attitude variables together to evaluate the mediating effect of academic performance. The result shows that attitude accounted for additional 34\% of variance towards academic performance ( $\mathrm{F}$ $(7,498)=9.150, \mathrm{p}=0.000)$.

Table 3: Standardized Beta Weights for Variables Predicting academic performance

\begin{tabular}{|c|c|}
\hline Demographic variables & $\begin{array}{c}\text { Academic } \\
\text { performance }\end{array}$ \\
\hline Age & $0.114^{*}$ \\
\hline Gender & $0.114^{* *}$ \\
\hline Education & 0.042 \\
\hline Accessibility & 0.036 \\
\hline Addictiveness & $0.175^{* * *}$ \\
\hline Exposure & 0.010 \\
\hline Communication & $0.238^{* * *}$ \\
\hline$* \mathrm{p}<0.05 * * \mathrm{p}<0.01 * * * \mathrm{p}=0.000$ \\
\hline
\end{tabular}

The above table 3points out a lower, but the equally significant beta weight for age, gender and academic performance. Additionally, addictiveness and communication in the social media attitude have a significant beta weight and significantly predicted academic performance. Hence, it is inferred that the age and gender in demographic variables and addictiveness and communication in the social media attitude were the best predictors of the dependent variable i.e., academic performance. To discern the distinctive contribution of social media attitude, especially collated to social media usage, an additional regression equation was executed using all previous variables and social media usage variables. The results of this test show $34 \%$ of the variance $(F(9,496)=7.206, p=$ 0.000 ) which indicates that there is no any additional significant change in relationships if usage variables were added. Hence, it is inferred that age, gender in demographic variables and addictiveness and communication in social media attitudes were the best predictors of academic performance. Education level (UG \&PG), accessibility, exposure and social media 
usage (weekdays, weekends) were not a significant predictor of academic performance.

\section{DISCUSSION :}

ICT has boosted the learning process by making it cheaper, faster and easily accessible which were not possible before. The collaborative learning atmosphere provided by ICT produces a better result. Researchers come with the notion that motivation and study time is the non-ability variables that significantly affect the academic performance of college students[8]. Contradicting the popular credence, academic performance is not directly influenced by the amount of time spent studying. The present study also indicates that in terms of the relationship between academic performance and social networking attitude it is predicated that when there is accessibility there is more addictiveness and exposure to social media attitude every day but it is not used for academic activities whereas only for other activities.Study mentioned that students prefer social media as a vital key for three purposes mainly[15], [20]. They are, for sharing and retrieval of information (educational purpose), coordinating the group work (management skills), and to clarify doubts. But this study proves that academic activities and official communication are being affected because of the usage of social networking at a higher level on all days for various other activities rather than academic purpose. Findings indicate that when social media were used as an additional teaching aid, the majority of the students showed strong feelings towards social connectedness and also expressed favourable and positive response when concerned with their learning experiences in the classroom environment[18], [19], [20], [21].

\section{CONCLUSION :}

Here the results of regression indicate that the respondents feel that they use social networking for having official communications and to have more exposure towards academic activities. Out of these four factors (Social media attitude, addictiveness, acceptability, and communication), only communication and addictiveness are the best predictors of academic performance. The other two factors such as exposure and the time spent do not have much influence on academic performance.

Note: The project on which the present report is funded by the Indian Council of Social Science Research. However, the responsibility for the facts stated, opinions expressed, and conclusions reached is entirely that of the project director/author and not of the Indian Council of Social Science Research.

\section{REFERENCES :}

[1] Rahman, H. (2006). ICT mediated learning for socio-economic empowerment.http://pcf4.dec.uwi.edu/viewpape r.php?id=261.

[2] Lupton, D. (2014). Feeling better connected: Academics' use of social media.p.36, Canberra : News Media Research Centre, University of Canberra.

[3] Bates, A.W. (2005). Technology, e-learning and distance education, (2nd Edition), Routledge.

[4] Harden, R. M. (2002). Developments in outcome-based education. Medical Teacher, 24(2), 117-120.

[5] Bennett, R. E. (2006). Inexorable and inevitable: The continuing story of technology and assessment. Computer-based testing and the Internet: Issues and advances, 1(1), 201-217.

[6] Borrás, I., \& Lafayette, R. C. (1994). Effects of multimedia courseware subtitling on the speaking performance of college students of French. The Modern Language Journal, 78(1), 61-75.

[7] Perry, R. P., Hechter, F. J., Menec, V. H., \& Weinberg, L. E. (1993). Enhancing achievement motivation and performance in college students: An attributional retraining perspective. Research in Higher Education, 34(6), 687-723.

[8] Nonis, S. A., \& Hudson, G. I. (2006). Academic performance of college students: Influence of time spent studying and working. Journal of Education for Business, 81(3), 151159. 
[9] Gollwitzer, P. M., \& Sheeran, P. (2006). Implementation intentions and goal achievement: A meta-analysis of effects and processes. Advances in experimental social psychology, 38, 69-119.

[10] Balduf, M. (2009). Underachievement among college students. Journal of advanced academics, 20(2), 274-294.

[11] Wolters, C. A. (1998). Self-regulated learning and college students' regulation of motivation. Journal of educational psychology, 90(2), 224.

[12] GortnerLahmers, A., \&Zulauf, C. R. (2000). Factors associated with academic time use and academic performance of college students: A recursive approach. Journal of College Student Development, 41(5), 544-556.

[13] Greene, B. A., Miller, R. B., Crowson, H. M., Duke, B. L., \&Akey, K. L. (2004). Predicting high school students' cognitive engagement and achievement: Contributions of classroom perceptions and motivation. Contemporary educational psychology, 29(4), 462-482.

[14] Pintrich, P. R., \& De Groot, E. V. (1990). Motivational and self-regulated learning components of classroom academic performance. Journal of educational psychology, 82(1), 33.

[15] Hrastinski, S., \&Aghaee, N. M. (2012). How are campus students using social media to support their studies? An explorative interview study. Education and Information Technologies, 17(4), 451-464.

[16] DeAndrea, D. C., Ellison, N. B., LaRose, R., Steinfield, C., \& Fiore, A. (2012). Serious social media: On the use of social media for improving students' adjustment to college. The Internet and higher education, 15(1), 15-23.

[17] Junco, R. (2014). Engaging students through social media: Evidence-based practices for use in student affairs. John Wiley \& Sons.
[18] Hung, H. T., \& Yuen, S. C. Y. (2010). Educational use of social networking technology in higher education. Teaching in higher education, 15(6), 703-714.

[19] Boobalakrishnan, N., Jayaseelan, R., \& Srinivasan, M. (2019). Social media and students' attitude: A study of accessibility, addictiveness, exposure and communication among college students in Coimbatore, Tamil Nadu. Mass Communicator: International Journal of Communication Studies, 13(1), 3238.

[20] Boobalakrishnan, N., Jayaseelan, R., \&Pichandy, C. (2020). An Empirical Study on Social Media usage by College Students in Coimbatore, India. Asian Journal of Multidisciplinary Studies, 3(1). 70-76. 